\title{
PHENOTYPIC TRAITS OF BROMUS INERMIS LEYSS AND ENVIRONMENTAL FACTORS ON THE NORTH SLOPE OF THE TIANSHAN MOUNTAINS
}

\author{
GONG, K. - JiN, G. L.* - WANG, Y. X. - LI, C. J. - YUE, Y. H. - HAN, W. Q. - LIU, W. H. - WU, X. E. \\ College of Grassland and Environmental Sciences, Xinjiang Agricultural University/Key \\ Laboratory of Grassland Resources and Ecology of Xinjiang, Urumqi 830052, China \\ (e-mail:1538095879@qq.com-K. Gong; phone: +86-185-9907-7363) \\ *Corresponding author \\ e-mail: jguili@126.com; phone: +86-189-0991-0602 \\ (Received $11^{\text {th }}$ May 2021; accepted $4^{\text {th }}$ Sep 2021)
}

\begin{abstract}
The adaptability of plants to heterogeneous environments demonstrates their phenotypic plasticity, and their responses to the environment are reflected mainly in their phenotypic traits and biomass allocation strategies. We selected 5 regions from west to east on the north slope of the Tianshan Mountains in Xinjiang to collect Bromus inermis, and the results showed that there were significant differences in phenotypic traits and biomass allocation patterns from west to east, indicating that this species has a strong ability to adapt to heterogeneous environments. The plant height, leaf characteristics and reproductive characteristics of $B$. inermis in the central study area were superior to of plants in other areas. The vegetative organs of $B$. inermis had greater variability and more biomass than the other organs, while the aboveground organ biomass showed a close relationship with the aboveground biomass allocation; the stem biomass distribution was the most representative of this relationship. We concluded that, in heterogeneous environments, $B$. inermis adjusts its phenotypic traits and biomass allocation mostly in response to differences in climate. In the study area, $B$. inermis adapted to guarantee its asexual growth and reduced its investment in sexual reproduction, which is in line with the reproductive mode of this rhizomatous plant.
\end{abstract}

Keywords: heterogeneous environments, biomass allocation, ecological adaptability

\section{Introduction}

Many plants grow in different heterogeneous environments within the geographical range to which they are adapted, and their organs undergo different degrees of variation in response to different environmental factors in their habitat in order to maintain plant growth and reproduction. In recent years, a new research perspective based on phenotypic traits has been used to focus on the influence of the relationship between different organs and habitats on growth and reproduction (Peltonen-Sainio et al., 2011; Sadras and Slafer, 2012; Slafer et al., 2014). Scholars have found that the leaves of plants at lower elevations are larger and that the morphological variation of flowers at higher elevations is more obvious (Olowa et al., 2018). The different forms of plant fruits and seeds correspond to the level of stress experienced by the maternal plant during its growth and development. Under severe water stress and the loss of its deciduous leaves, the production of no dehiscent fruit in Cruciferae plants will increase. Plants with strong phenotypic plasticity can live in a variety of habitats, which provides them with more opportunities to reproduce in complex environments and avoid various types of risk (Lu et al., 2012).

During the process of plant growth, the availability of resource inputs is reflected in the response and adaptability of plant development and reproduction in relation to the environment. When plant growth is affected by a lack of soil resources such as water or 
nutrients, the plant will allocate more biomass to the roots (Xu et al., 2012). Conversely, if the plant is constrained by light resources, the plant will allocate more biomass to the leaves to ensure consistent light intake by the plant (Luo et al., 2012). These changes represent the response of plants to stressful environments, and differences in location and elevation can also lead to different biomass allocation patterns within the same plant species. One elevation-related change that has been commonly found in previous studies is that with increasing elevation, alpine plants allocate more biomass to their belowground parts, leading to a significant decline in stem biomass (Olowa et al., 2018). This response indicates that as the elevation increases, the amount of energy the environment provides for plant growth decreases, as does the amount of energy the plants themselves need. Therefore, to ensure their survival, plants must allocate more resources to their reproductive organs, complete their life cycle and thereby increase the reproductive rate of the population (Yang et al., 2020).

Plants respond to different environments by changing their phenotypes or adjusting their biomass allocation patterns, which indicates that the organ area and volume of plants are two factors determining plant access to resources (Bradshaw, 1965; Pang and Lercher, 2015). Scholars have often used comparative morphology and biological mathematics to analyse and evaluate the phenotypic traits of plants, distinguish the morphological differences between different germplasms, classify their status and groupings, and finally select qualified breeding materials to provide high-quality materials for cultivation (Duruflé et al., 2019).

Environmental factors are often considered important statistical parameters in explaining the influence of heterogeneity on phenotypic variations among different environments (Zheng et al., 2019). However, we found that environmental impacts can be observed as the differences in plant traits between geographic populations. The influence of genetic variation is typically more concentrated in the interior of a population than at the edge of the population range. Character variation also occurs within and between geographic populations in total variation models, leading to gradual changes in plant growth (Morgenstern, 2011; McKown et al., 2014).

Xinjiang is located in Central Asia and the Central Asian desert transition or intersection area. Natural Bromus inermis is distributed across a broad longitudinal and latitudinal range in a mountainous region, and there are notable topographic and atmospheric differences in the environment within this range. Therefore, the phenotypic traits and biomass allocation strategies of $B$. inermis have evolved to adapt to these environments under the influence of many factors. The characteristic ecological adaptability of this group has resulted in the development of a rich germplasm resource gene pool. B. inermis has the same adaptive characteristics as Leymus chinensis, Dactylis glomerata and other plants of similar research value (Li et al., 2015; Zhang et al., 2015; Wang et al., 2011); in addition, other relevant studies on herbage have been published in recent years (Zhao et al., 2016; Ott et al., 2017; Yuan et al., 2019).

$B$. inermis is a perennial rhizomatous grass that is traditionally used for grazing or fodder. Wild $B$. inermis is distributed in the temperate regions of Asia, Europe and North America and is widely distributed in many regions of China. Natural B. inermis in Xinjiang is distributed mainly within a range that is $1500 \sim 2400 \mathrm{~m}$ north of the Tianshan Mountains, 92.986 $\sim 80.766^{\circ}$ east longitude, $43.074^{\circ} \sim 48.701^{\circ}$ north latitude, and mostly in meadow grassland. Previous studies have shown that $B$. inermis exhibits high growth adaptability after invading other grasslands and could perform a series of life activities, such as settlement and expansion, by changing its phenotypic 
traits and biomass allocation strategies (Salesman and Thomsen, 2011; Stotz et al., 2016; Ott et al., 2017); it can also occupy an important ecological niche in mixed plantings (Ulrich and Perkins, 2014; Biligetu and Coulman, 2011). After artificial stress, it can actively adjust its own structure to avoid growth retardation by responding rapidly to various influencing factors (Woodis and Jackson, 2010; Lermi et al., 2018; Majidi et al., 2017). In conclusion, B. inermis shows strong adaptability in both natural and human conditions, which has enabled the population to expand and reproduce by changing its phenotype. However, the physiological traits of $B$. inermis have not yet been examined in detail. In this study, the following questions were addressed: (1) Are there differences in phenotypic characteristics among different natural populations of $B$. inermis? (2) What are the effects of climatic factors and soil factors on B. inermis?

\section{Material and methods}

\section{Study sites}

B. inermis is widely distributed in Jilin, Liaoning, Inner Mongolia, Hebei, Shanxi, Shandong, Jiangsu, Shaanxi, Gansu, Qinghai, Xinjiang, Xizang, Yunnan, Sichuan, Guizhou and other provinces (regions) in China. It mainly grows in meadow steppe, alpine meadow and mountain meadow environments. It is the dominant species in mountain meadow ecosystems at $1000 \sim 3500 \mathrm{~m}$. It has become an important cultivated forage in arid and cold regions of China.

The study was performed on the north slope of the Tianshan Mountains (80.910$93.755^{\circ} \mathrm{E}, 43.109-43.836^{\circ} \mathrm{N}$ ), where there is a typical distribution of $B$. inermis. The north slope of the Tianshan Mountains, including the western, central and eastern sections of the Tianshan Mountain foothills, is located in the north of the Tarim Basin, where the terrain is high in the south and low in the north. The distinct topography influences the local climatic conditions mainly by causing differences in temperature and rainfall, which have an impact on the growth and reproduction of plant populations. Therefore, it is appropriate to study the adaptive growth of plants in different regions of the Tianshan Mountains.

From west to the east along the mountain, we selected 5 grasslands in which $B$. inermis was the dominant species or a subdominant species. The selected grasslands were located in Zhaosu County, Hutubi County, Urumqi County, Qitai County and Balikun County. All the selected grasslands are protected by fences and are not disturbed by livestock feeding (Figs. 1 and 2).

\section{Experimental design}

In the 5 selected regions, we need to accurately determine the distribution range of $B$. inermis. According to the actual distribution, three sample plots were evenly arranged along the elevation range of the distribution area, and each sample plot was $10 \times 10 \mathrm{~m}$. Geographic information on each sample plot was recorded, including longitude, latitude and elevation. Complete single plants (including roots) representing the average level of the plot were randomly extracted from the plot, and 30 plants were extracted from each plot, yielding a total of 90 samples of $B$. inermis from the 3 plots at different elevations.

Because the elevation fluctuates greatly in the Tianshan Mountains, the elevation of each region is not the same, and the differences are large. We uniformly refer to the sites in each region as the low-elevation, medium-elevation and high-elevation sites to 
describe the specific distribution location of $B$. inermis in each area, rather than the actual elevation range. Therefore, the high-elevation site in one region may be lower than the low-elevation site in another region, but this is does not influence our comparison. We only pay attention to the relationship between different elevation positions in a single region.



Figure 1. Map of the study sites


Figure 2. Research area status 


\section{Climatic and edaphic data}

The meteorological data of the five selected regions, including annual mean temperature and annual precipitation, were calculated using the interpolation method based on 30 years of data (1989-2019) provided by the meteorological stations of The National Meteorological Data Center of China. It is important to note that we have calculated the averages of the meteorological data for each region's meteorological data. Therefore, we use meteorological data for each region rather than for each elevation. The changes in elevation are not associated with dramatic differences in geographical location, and the climatic factors change little; thus, we do not use these data (Table 1).

Table 1. Geographic information and meteorological information for the sampling area

\begin{tabular}{|c|c|c|c|c|c|c|}
\hline Origin & \multicolumn{2}{|c|}{ Elevation (m) } & Longitude & Latitude & $\begin{array}{l}\text { Annual average } \\
\text { temperature }\left(^{\circ}\right)\end{array}$ & $\begin{array}{c}\text { Average annual } \\
\text { precipitation (mm) }\end{array}$ \\
\hline \multirow{3}{*}{$\begin{array}{l}\text { Zhaosu } \\
\text { County }\end{array}$} & Low & 1790 & E $80.910^{\circ}$ & $\mathrm{N} 43.109^{\circ}$ & \multirow{3}{*}{5.9} & \multirow{3}{*}{559.6} \\
\hline & Medium & 1980 & E $80.914^{\circ}$ & $\mathrm{N} 43.111^{\circ}$ & & \\
\hline & High & 2100 & E $80.922^{\circ}$ & $\mathrm{N} 43.170^{\circ}$ & & \\
\hline \multirow{3}{*}{$\begin{array}{l}\text { Hutubi } \\
\text { County }\end{array}$} & Low & 1574 & E $87.329^{\circ}$ & $\mathrm{N} 43.836^{\circ}$ & \multirow{3}{*}{7.3} & \multirow{3}{*}{193.8} \\
\hline & Medium & 1598 & E $87.035^{\circ}$ & $\mathrm{N} 43.514^{\circ}$ & & \\
\hline & High & 1616 & E $87.330^{\circ}$ & $\mathrm{N} 43.836^{\circ}$ & & \\
\hline \multirow{3}{*}{$\begin{array}{l}\text { Urumqi } \\
\text { County }\end{array}$} & Low & 1630 & E $87.029^{\circ}$ & $\mathrm{N} 43.516^{\circ}$ & \multirow{3}{*}{1.3} & \multirow{3}{*}{257.0} \\
\hline & Medium & 1670 & E $87.040^{\circ}$ & $\mathrm{N} 43.502^{\circ}$ & & \\
\hline & High & 1960 & E $87.042^{\circ}$ & $\mathrm{N} 43.483^{\circ}$ & & \\
\hline \multirow{3}{*}{$\begin{array}{c}\text { Qitai } \\
\text { County }\end{array}$} & Low & 1574 & E $89.329^{\circ}$ & $\mathrm{N} 43.836^{\circ}$ & \multirow{3}{*}{7.8} & \multirow{3}{*}{185.0} \\
\hline & Medium & 1810 & E $89.600^{\circ}$ & $\mathrm{N} 43.617^{\circ}$ & & \\
\hline & High & 1853 & E $89.587^{\circ}$ & $\mathrm{N} 43.625^{\circ}$ & & \\
\hline \multirow{3}{*}{$\begin{array}{l}\text { Bailikun } \\
\text { County }\end{array}$} & Low & 2107 & E $93.751^{\circ}$ & $\mathrm{N} 43.329^{\circ}$ & \multirow{3}{*}{2.4} & \multirow{3}{*}{230.8} \\
\hline & Medium & 2206 & E $93.754^{\circ}$ & $\mathrm{N} 43.328^{\circ}$ & & \\
\hline & High & 2298 & E $93.755^{\circ}$ & $\mathrm{N} 43.327^{\circ}$ & & \\
\hline
\end{tabular}

Three soil samples from the $0-5 \mathrm{~cm}, 5-10 \mathrm{~cm}$ and $10-15 \mathrm{~cm}$ layers were taken in each sample plot. The samples were first combined, and then the soil samples were prepared by quartering. Each quartered sample was air-dried and then sieved through a $1 \mathrm{~mm}$ sieve to remove chunks of rock and plant roots. The soil $\mathrm{pH}$ was measured by using a potentiometer. The organic matter content (soil organic carbon) was measured by the potassium dichromate heating method. The total nitrogen was measured by the Kjeldahl procedure. The total phosphorus was measured by the Mo-Sb colorimetric method (Table 2).

Table 2. Soil physical and chemical characteristics in the sampling area

\begin{tabular}{c|c|c|c|c}
\hline Origin & $\mathbf{P H}$ & $\mathbf{N}(\mathbf{g} / \mathbf{k g})$ & $\mathbf{P}(\mathbf{g} / \mathbf{k g})$ & $\mathbf{K}(\mathbf{g} / \mathbf{k g})$ \\
\hline Zhaosu County & $7.01 \pm 0.18$ & $4.98 \pm 0.45$ & $0.03 \pm 0.003$ & $11.82 \pm 2.46$ \\
Hutubi County & $7.64 \pm 0.16$ & $4.97 \pm 0.52$ & $0.03 \pm 0.003$ & $9.90 \pm 0.27$ \\
Urumqi County & $7.39 \pm 0.05$ & $2.59 \pm 1.23$ & $0.03 \pm 0.003$ & $8.54 \pm 0.01$ \\
Qitai County & $6.90 \pm 0.47$ & $5.67 \pm 0.91$ & $0.04 \pm 0.003$ & $10.67 \pm 0.27$ \\
Bailikun County & $7.61 \pm 0.16$ & $4.92 \pm 1.48$ & $0.04 \pm 0.006$ & $10.09 \pm 0.01$ \\
\hline
\end{tabular}




\section{Phenotypic index determination}

We selected 12 phenotypic indicators to measure in $B$. inermis, including the reproductive branch height, vegetative branch height, stem diameter, spike length, root length, leaf length, leaf width, inflorescence length, and inflorescence width. The leaf index and inflorescence index were measured 3 times. We also counted the tiller number in each plot and recorded the thousand-grain weight for the sampled plants.

\section{Biomass determination}

The $B$. inermis plants that had been measured were carefully cut into stems, leaves, spikes and roots. Each part of the plant was weighed separately, and the undried weight of each component was recorded.

The root mass ratio (RMR, root weight/total plant weight), leaf mass ratio (LMR, leaf weight/total plant weight), spike mass ratio (SMR, spike weight/total plant weight), belowground storage organ biomass ratio (belowground storage organ weight/total plant weight), and aboveground biomass ratio (shoot weight/total plant weight) were calculated. The nutrient acquisition organ biomass ratio (root weight, stem weight and leaf weight/total plant weight) and the reproductive component organ biomass ratio (spike weight/total plant weight) were also calculated.

\section{Data analysis}

The $\mathrm{F}$ test was used to preliminarily verify the assumption of homogeneity. Then, ANOVA was used to analyse the differences between the phenotypic morphological indexes and component biomass indexes in the different regions. Multiple comparison analyses were performed on the trait differences in $B$. inermis among the 3 elevations and 5 regions, and the variation coefficients of each index in the 5 regions were calculated. The differences in biomass allocation to plant components (belowground and aboveground biomass, vegetative biomass and reproductive biomass) among regions were analysed. Principal component analysis (PCA) was used to evaluate the main trait factors that influenced the traits of $B$. inermis, and the relevance of variables was determined according to the direction, orientation and magnitude of their vectors. The response of the biomass of the abovementioned components to the biomass allocation was analysed by linear regression.

\section{Results}

\section{The influence of region and elevation on trait indexes}

The altitudinal gradient and the different regions had different effects on the phenotypic growth of $B$. inermis (Table 3). Elevation significantly influenced the main stem diameter but had no effect on the other indexes. However, the phenotypes still varied among elevation levels. Six indexes gradually increased with elevation, such as the leaf length, inflorescence width, thousand-grain weight, leaf mass ratio, supporting organ biomass ratio and spike mass ratio, with an increase range of 5.57\%-19.75\% and an average growth rate of $10.26 \%$. However, the vegetative branch height, reproductive branch height and ear length reached their maximum at the medium elevation, with an average increase of $9.53 \%$ over the lowest values. The remaining 3 indexes, tiller number, stem diameter and leaf width, reached their maximum values at 
low elevations, with an average growth rate of $18.72 \%$. Additionally, the effects of region and elevation on tiller number and stem diameter were not significant. In summary, the growth rate of $B$. inermis at low elevations is faster than that at high elevations, while the biomass accumulation of $B$. inermis at high elevations is greater than that at low elevations.

Table 3. Mean values ( \pm SE) and significance levels from the two-way ANOVA of trait indexes

\begin{tabular}{c|c|c|c|c|c|c}
\hline \multirow{2}{*}{ Variable } & \multicolumn{3}{|c|}{ Elevation } & \multicolumn{3}{c}{ ANOVA } \\
\cline { 2 - 7 } & Low & Medium & High & $\begin{array}{c}\text { Region } \\
\text { (R) }\end{array}$ & $\begin{array}{c}\text { Elevation } \\
\text { (E) }\end{array}$ & R $\times \mathbf{E}$ \\
\hline Tiller number & $2.83 \pm 2.75$ & $1.79 \pm 1.67$ & $2.35 \pm 2.28$ & $\mathrm{~ns}$ & $\mathrm{~ns}$ & $\mathrm{~ns}$ \\
Reproductive branch height & $88.02 \pm 22.33$ & $91.54 \pm 18.76$ & $83.13 \pm 28.85$ & $*$ & $\mathrm{~ns}$ & $*$ \\
Vegetative branch height & $25.97 \pm 13.95$ & $28.90 \pm 14.63$ & $28.45 \pm 20.12$ & $* *$ & $\mathrm{~ns}$ & $\mathrm{~ns}$ \\
Leaf length & $1.97 \pm 0.60$ & $1.82 \pm 0.45$ & $1.83 \pm 0.53$ & $*$ & $*$ & $\mathrm{~ns}$ \\
Leaf width & $10.95 \pm 4.01$ & $12.41 \pm 5.45$ & $12.50 \pm 5.04$ & $* *$ & $\mathrm{~ns}$ & $\mathrm{~ns}$ \\
Spike length & $4.54 \pm 1.76$ & $4.23 \pm 1.718$ & $3.81 \pm 1.04$ & $* *$ & $\mathrm{~ns}$ & $\mathrm{~ns}$ \\
Root length & $12.27 \pm 6.85$ & $11.16 \pm 5.38$ & $11.62 \pm 4.75$ & $\mathrm{~ns}$ & $\mathrm{~ns}$ & $\mathrm{~ns}$ \\
Inflorescence length & $12.91 \pm 4.42$ & $13.83 \pm 3.67$ & $13.27 \pm 5.97$ & $* * *$ & $\mathrm{~ns}$ & $*$ \\
Inflorescence width & $20.14 \pm 4.72$ & $19.66 \pm 4.19$ & $18.61 \pm 5.02$ & $\mathrm{~ns}$ & $\mathrm{~ns}$ & $\mathrm{~ns}$ \\
Stem diameter & $2.06 \pm 0.81$ & $2.17 \pm 0.71$ & $2.17 \pm 0.77$ & $\mathrm{~ns}$ & $\mathrm{~ns}$ & $\mathrm{~ns}$ \\
Thousand-grain weight & $2.42 \pm 0.44$ & $2.56 \pm 0.44$ & $2.59 \pm 0.29$ & $* * *$ & $\mathrm{~ns}$ & $* *$ \\
SBR & $36.23 \pm 14.43$ & $38.00 \pm 16.83$ & $39.61 \pm 17.83$ & $\mathrm{~ns}$ & $\mathrm{~ns}$ & $\mathrm{~ns}$ \\
LMR & $38.20 \pm 15.30$ & $37.46 \pm 16.36$ & $35.30 \pm 15.95$ & $\mathrm{~ns}$ & $\mathrm{~ns}$ & $\mathrm{~ns}$ \\
RMR & $16.83 \pm 11.72$ & $14.15 \pm 10.70$ & $16.94 \pm 11.93$ & $*$ & $\mathrm{~ns}$ & $\mathrm{~ns}$ \\
SMR & $8.07 \pm 6.74$ & $7.72 \pm 7.17$ & $8.15 \pm 8.17$ & $*$ & $\mathrm{~ns}$ & $\mathrm{~ns}$ \\
\hline
\end{tabular}

*Significant correlation at the $<0.05$ level. **Significant correlation at the $<0.01$ level

In contrast, the various regions had a more significant influence on phenotype and biomass than the different elevations and had a significant influence on all indicators except tiller number, root length, spikelet traits, and stem and root biomass. However, these indicators were not significantly influenced by the interactive effect of region and elevation, indicating that these indicators may be more influenced by genetic variation than by environmental factors. Among the trait indexes, spike length and thousand-grain weight were the most significantly influenced by region $(P<0.01)$. As shown in Table 4, the spike length and thousand-grain weight in Urumqi County were significantly higher than those in the other regions and were higher than the minimum values by $96.27 \%$ and $37.88 \%$, respectively. They first increased and then decreased from west to east along the north slope of the Tianshan Mountains, and the height index, leaf index and grain quality also showed the same pattern. However, the stem diameter and root length in Hutubi County were significantly higher than those in other regions, with an average increase of $45.75 \%$ above the minimum value. The results indicated that there were more significant differences in B. inermis between regions than between elevations, suggesting the main influences on $B$. inermis phenotype and biomass are regional. At the same time, it can be seen that the $B$. inermis plants in the central part of the north slope of the Tianshan Mountains are tall, with a high leaf area, few leaves, and large panicle grains; therefore, these plants have more potential for genetic development than those from other areas. 
Table 4. Mean values $( \pm S E)$ of indicators among different regions

\begin{tabular}{c|c|c|c|c|c}
\hline \multirow{2}{*}{ Variable } & \multicolumn{5}{|c}{ Region } \\
\cline { 2 - 6 } & Zhaosu County & Hutubi County & Urumqi County & Qitai County & Balikun County \\
\hline Reproductive branch height & $78.92 \pm 17.93 \mathrm{~b}$ & $106.89 \pm 16.30 \mathrm{c}$ & $107.34 \pm 25.93 \mathrm{c}$ & $69.93 \pm 10.81 \mathrm{a}$ & $76.09 \pm 15.59 \mathrm{ab}$ \\
Vegetative branch height & $28.44 \pm 14.06 \mathrm{~b}$ & $40.83 \pm 10.72 \mathrm{c}$ & $44.36 \pm 19.68 \mathrm{c}$ & $16.59 \pm 7.14 \mathrm{a}$ & $19.19 \pm 6.75 \mathrm{a}$ \\
Stem diameter & $1.51 \pm 0.29 \mathrm{a}$ & $2.27 \pm 0.48 \mathrm{c}$ & $2.19 \pm 0.65 \mathrm{~b}$ & $1.67 \pm 0.31 \mathrm{a}$ & $1.90 \pm 0.46 \mathrm{~b}$ \\
Leaf length & $7.64 \pm 1.88 \mathrm{a}$ & $15.42 \pm 3.36 \mathrm{c}$ & $16.19 \pm 3.95 \mathrm{c}$ & $8.87 \pm 2.19 \mathrm{a}$ & $11.81 \pm 5.30 \mathrm{~b}$ \\
Leaf width & $2.75 \pm 0.62 \mathrm{a}$ & $3.92 \pm 0.85 \mathrm{~b}$ & $5.96 \pm 1.94 \mathrm{~d}$ & $3.75 \pm 0.80 \mathrm{~b}$ & $4.56 \pm 1.05 \mathrm{c}$ \\
Root length & $9.72 \pm 5.86 \mathrm{a}$ & $13.73 \pm 5.08 \mathrm{c}$ & $12.07 \pm 4.91 \mathrm{bc}$ & $11.27 \pm 6.36 \mathrm{ab}$ & $11.73 \pm 5.64 \mathrm{abc}$ \\
Spike length & $8.82 \pm 3.03 \mathrm{a}$ & $16.60 \pm 3.32 \mathrm{~d}$ & $17.31 \pm 5.05 \mathrm{~d}$ & $10.75 \pm 2.74 \mathrm{~b}$ & $13.35 \pm 2.90 \mathrm{c}$ \\
Thousand-grain weight & $2.38 \pm 0.23 \mathrm{a}$ & $2.51 \pm 0.31 \mathrm{a}$ & $3.03 \pm 0.32 \mathrm{~b}$ & $2.49 \pm 0.40 \mathrm{a}$ & $2.20 \pm 0.12 \mathrm{a}$ \\
LMR & $14.31 \pm 10.44 \mathrm{a}$ & $14.44 \pm 14.61 \mathrm{a}$ & $13.68 \pm 11.27 \mathrm{a}$ & $15.35 \pm 9.74 \mathrm{a}$ & $21.95 \pm 9.01 \mathrm{~b}$ \\
SMR & $5.89 \pm 4.89 \mathrm{a}$ & $3.64 \pm 3.85 \mathrm{a}$ & $10.67 \pm 6.04 \mathrm{~b}$ & $10.43 \pm 7.87 \mathrm{~b}$ & $9.03 \pm 9.84 \mathrm{~b}$ \\
\hline
\end{tabular}

Different lowercase letters above the columns indicate significant differences at $P<0.05$

\section{Variation in phenotypic indicators and biomass allocation within the 5 regions}

Comparing traits within each region along the north slope of the Tianshan Mountains revealed that each index varied greatly (Table 5) but that the variation within each region did not exhibit regularity. Overall, the phenotypic traits of $B$. inermis on the north slope of the Tianshan Mountains were different, but the degree of variation was small. The variation in biomass allocation was very small within all regions and overall. Moreover, when there were differences among regions, the differences were not in the main indexes of concern. The variation range of the 11 trait indexes among all regions ranged from 0.126 to 0.700 . Among them, the degree of variation in the tiller number, root length and vegetative branch height (vegetative organ traits) was high, at 0.541 , 0.485 and 0.397 , respectively; the degree of variation in the panicle length and spikelet width (reproductive organs) was also high, at 0.261 and 0.274 , respectively.

Table 5. The coefficient of variation for each index in the 5 regions and the total coefficient of variation for each index

\begin{tabular}{c|c|c|c|c|c|c}
\hline \multirow{2}{*}{ Variable } & \multicolumn{7}{|c|}{ Region } & \multirow{2}{*}{$\begin{array}{c}\text { Total coefficient } \\
\text { of variation }\end{array}$} \\
\cline { 2 - 5 } & $\begin{array}{c}\text { Zhaosu } \\
\text { County }\end{array}$ & $\begin{array}{c}\text { Hutubi } \\
\text { county }\end{array}$ & $\begin{array}{c}\text { Urumqi } \\
\text { County }\end{array}$ & $\begin{array}{c}\text { Qitai } \\
\text { County }\end{array}$ & $\begin{array}{c}\text { Balikun } \\
\text { County }\end{array}$ & 0.541 \\
Tiller number & 0.462 & 0.539 & 0.355 & 0.700 & 0.647 & 0.196 \\
Reproductive branch height & 0.227 & 0.152 & 0.242 & 0.155 & 0.205 & 0.397 \\
Vegetative branch height & 0.494 & 0.263 & 0.444 & 0.43 & 0.352 & 0.226 \\
Leaf length & 0.191 & 0.210 & 0.297 & 0.186 & 0.244 & 0.281 \\
Leaf width & 0.247 & 0.218 & 0.244 & 0.247 & 0.449 & 0.242 \\
Spike length & 0.225 & 0.216 & 0.325 & 0.213 & 0.230 & 0.485 \\
Root length & 0.603 & 0.370 & 0.407 & 0.564 & 0.481 & 0.261 \\
Inflorescence length & 0.343 & 0.200 & 0.292 & 0.255 & 0.218 & 0.217 \\
Inflorescence width & 0.227 & 0.177 & 0.334 & 0.174 & 0.175 & 0.274 \\
Stem diameter & 0.296 & 0.356 & 0.332 & 0.126 & 0.261 & 0.109 \\
Thousand-grain weight & 0.097 & 0.123 & 0.107 & 0.163 & 0.056 & 0.021 \\
SBR & 0.047 & 0.037 & 0.041 & 0.039 & 0.045 & 0.020 \\
LMR & 0.049 & 0.043 & 0.054 & 0.038 & 0.036 & 0.034 \\
RMR & 0.077 & 0.110 & 0.087 & 0.067 & 0.043 & 0.044 \\
SMR & 0.088 & 0.115 & 0.060 & 0.080 & 0.115 & \\
\hline
\end{tabular}




\section{Effect of region on the biomass of each plant component}

The biomass distribution ratios for the reproductive biomass and nutrient acquisition biomass of B. inermis were determined for the different regions (Fig. 3a). The biomass allocation to nutrient acquisition organs in all 5 regions was greater than $80 \%$, and there were significant differences among regions $(P<0.05)$. B. inermis in Urumqi County, Qitai County and Balikun County allocated significantly more biomass to reproductive components than that in Zhaosu County and Hutubi County. In summary, in the five $B$. inermis regions, more biomass was allocated the stem, leaf and root to ensure adequate nutrient storage and growth in $B$. inermis.
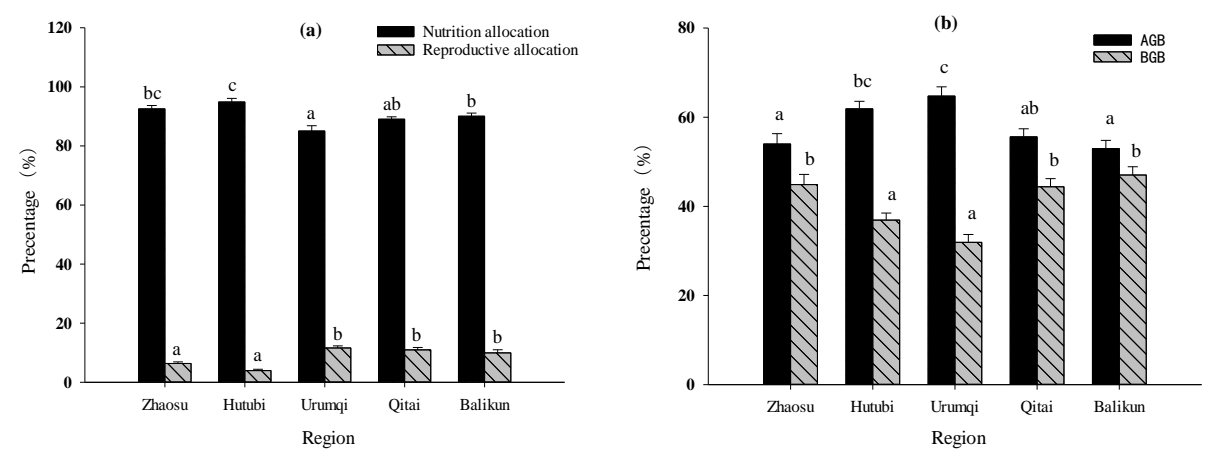

Figure 3. (a) Reproductive and nutrient-acquiring biomass and (b) aboveground biomass and belowground biomass in the five regions. Different lowercase letters above the columns indicate significant differences at $P<0.05$

The aboveground and belowground biomass of $B$. inermis in different regions (Fig. 3b) exhibited different patterns. Aboveground biomass was significantly higher than belowground biomass $(P<0.05)$, and the highest proportion of aboveground biomass was observed in Urumqi County $(64.75 \%)$. The highest proportion of belowground biomass was in Balikun County, at $47.04 \%$ of the total biomass. The belowground biomass values in Urumqi County and Hutubi County were significantly lower those that in other regions $(P<0.05)$. Thus, along the north slope of the Tianshan Mountains from west to east, the aboveground biomass distribution of $B$. inermis first increased and then decreased, while the belowground biomass showed the opposite trend. The results showed that the habitat in the central part of the study region was more favourable to the growth of the aboveground parts of $B$. inermis; as a result, the yield of the forage parts of $B$. inermis was increased. In the western and eastern parts of the study area, the belowground biomass was higher than in the central part to ensure adequate water and nutrients for $B$. inermis.

\section{The response of each indicator to environmental factors}

Climate factors had more influence on the $B$. inermis phenotype and biomass than soil factors (Table 6). In terms of topographic factors, elevation had an extremely significant correlation with each index except root length and spike mass ratio. The results of the differential analysis showed that the leaf width, root length and spikelet length reached maximum values at the lowest elevation, and the correlation analysis was consistent with these results. There was no correlation between the thousand-grain 
weight, root mass ratio and geographical location, while the correlations between vegetative branch height, leaf mass ratio, spike mass ratio and geographical location were weak; the correlations of the other indexes were generally highly significant. Most of the indicators for $B$. inermis reached maximum values in the central part of the study area, and the indicators did not show a trend of gradually increasing or decreasing with increasing latitude from west to the east on the north slope of the Tianshan Mountains.

Similarly, in the correlation analysis, most indicators were correlated with the latitude, but the correlation coefficients of these relationships were small. The average annual temperature was not correlated with root length or spike length, and the average annual precipitation was not correlated with leaf length or spike width; these climate factors were correlated with the other indexes for $B$. inermis. The average annual temperature and average annual precipitation had little influence on the reproductive components and storage components of $B$. inermis and were more strongly correlated with plant size and biomass traits. The vegetative branch height decreased with increasing $\mathrm{N}$ and $\mathrm{K}$ in the soil. Similarly, an increase in $\mathrm{N}$ also decreased the thousandgrain weight, while an increase in $\mathrm{K}$ decreased the stem mass ratio and increased the leaf mass ratio. The correlations between reproductive branch height and leaf width, spike length, stem diameter and thousand-grain weight were highly significant.

Table 6. Correlations between phenotypic traits of Bromus inermis and geographical factors

\begin{tabular}{c|c|c|c|c|c|c|c|c}
\hline \multirow{2}{*}{ Trait } & \multicolumn{9}{|c}{ Climatic factor } & \multicolumn{3}{c}{ Edaphic factor } \\
\cline { 2 - 8 } & Elevation & Longitude & Latitude & AMT & AMP & N & K & PH \\
\hline Tiller number & $0.197^{* *}$ & $0.114^{*}$ & $-0.145^{* *}$ & $0.165^{* *}$ & $-0.181^{* *}$ & 0.036 & 0.208 & 0.075 \\
Reproductive branch height & $-0.330^{* *}$ & $-0.130^{* *}$ & $0.171^{* *}$ & $-0.515^{* *}$ & $0.417^{* *}$ & -0.054 & -0.216 & 0.070 \\
Vegetative branch height & $-0.280^{* *}$ & $-0.301^{* *}$ & 0.042 & $-0.589^{* *}$ & $0.509^{* *}$ & $-0.286^{*}$ & $-0.486^{* *}$ & 0.221 \\
Leaf length & $-0.236^{* *}$ & $0.181^{* *}$ & $0.278^{* *}$ & $-0.143^{* *}$ & 0.052 & 0.142 & 0.051 & 0.200 \\
Leaf width & $-0.221^{* *}$ & $0.181^{* *}$ & $0.282^{* *}$ & $-0.291^{* *}$ & $0.0148^{* *}$ & -0.120 & -0.056 & $0.316^{*}$ \\
Spike length & $-0.176^{* *}$ & $0.313^{* *}$ & $0.181^{* *}$ & -0.065 & -0.080 & -0.186 & 0.110 & $0.483^{* *}$ \\
Root length & $-0.109^{*}$ & $0.095^{*}$ & $0.167^{* *}$ & -0.027 & -0.005 & -0.032 & 0.031 & -0.220 \\
Inflorescence length & $-0.225^{* *}$ & $0.222^{* *}$ & $0.326^{* *}$ & $-0.244^{* *}$ & $0.103^{*}$ & 0.077 & 0.032 & 0.225 \\
Inflorescence width & $0.212^{* *}$ & $0.218^{* *}$ & $-0.121^{*}$ & $0.269^{* *}$ & $-0.290^{* *}$ & -0.144 & 0.041 & 0.221 \\
Stem diameter & $0.406^{* * *}$ & $0.504^{* *}$ & $-0.160^{* *}$ & $0.318^{* *}$ & $-0.439^{* *}$ & 0.068 & 0.181 & $0.303^{*}$ \\
Thousand-grain weight & $-0.433^{* *}$ & -0.186 & 0.127 & $-0.430^{* *}$ & $0.372^{* *}$ & $-0.407^{* *}$ & -0.282 & $0.415^{* *}$ \\
SBR & $-0.256^{* *}$ & $-0.243^{* *}$ & $0.105^{*}$ & $-0.371^{* *}$ & $0.362^{* *}$ & -0.208 & $-0.358^{* *}$ & 0.142 \\
LMR & $0.194^{* *}$ & $0.204^{* *}$ & -0.061 & $0.198^{* *}$ & $-0.222^{* *}$ & 0.143 & $0.287^{* *}$ & -0.129 \\
RMR & $0.127^{* *}$ & 0.059 & -0.071 & $0.225^{* *}$ & $-0.180^{* *}$ & 0.162 & 0.179 & -0.233 \\
SMR & $0.101^{*}$ & $0.165^{* *}$ & 0.043 & $0.169^{* *}$ & $-0.188^{* *}$ & -0.105 & -0.003 & 0.276 \\
\hline
\end{tabular}

\section{The correlation between aboveground biomass and aboveground components}

The yield of $B$. inermis, as a good forage, is provided by the aboveground portion of the plant, which we measure as the aboveground biomass. Biomass is the content of the overall expression. To explore the relationship between the total biomass and the biomass of aboveground components is of great significance in exploring the influence of the environment on the growth of components and how it is reflected in the yield. Aboveground biomass showed a significant positive correlation with stem biomass, leaf biomass and spike biomass, and their responses to aboveground biomass showed a linear pattern (Fig. 4). With the increase in aboveground biomass, the biomass allocated to the 
aboveground components increased; the increase in stem biomass was the most obvious, followed by the increases in leaf and spike biomass. The results showed that when the aboveground biomass of $B$. inermis increased, the stem obtained more resources to promote plant growth; however, the spike began to need the majority growth resources during the middle of the growth period, so the biomass allocated to the stem decreased.

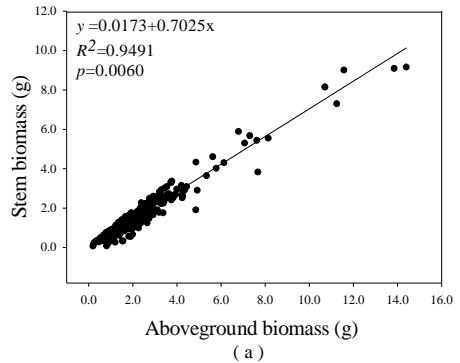

( a )

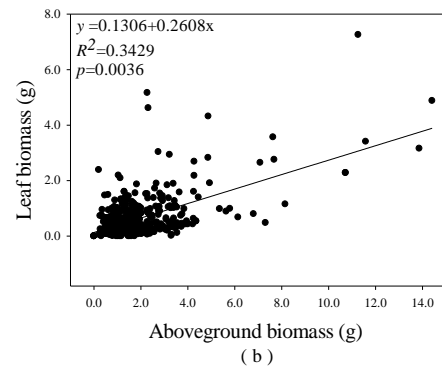

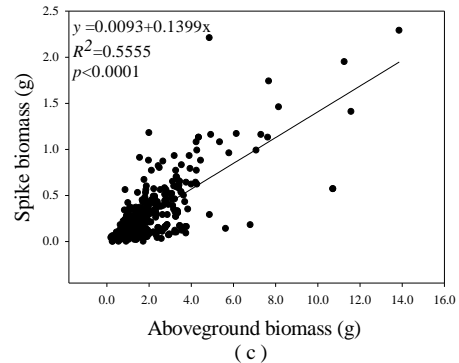

Figure 4. Relationship between aboveground biomass and stem biomass (a), leaf biomass (b), and spike biomass (c)

\section{Discussion}

\section{Adaptability of phenotypic traits to the environment}

The long-term interaction between plants and the environment is reflected in the external form of plants as they minimize the negative impacts of adverse environments (Meng et al., 2007). We observed varying degrees of difference in individual phenotypic plasticity in $B$. inermis within the same mountain range and in different environments. Therefore, plants should be considered in the context of various factors when discussing their ability to respond to heterogeneous environments by, for example, changing their phenotypic characteristics and component biomass allocation. However, first, we need to understand the similarities and differences in plant phenotypic characteristics and biomass allocation. Geographical location controls the combination of and differences in environmental factors, and the responses of plants along geographical gradients represent a model for a "natural experiment" (Stotz et al., 2017). We adopted an in situ sampling method, which is one of the most convenient ways to study the phenotypic variation of plants in their natural state. It can help us to effectively understand the environmental factors that affect the variation in natural populations and to explore the ecological effects of these factors more effectively (Bobowicz and kowa, 1986).

Vegetation is densely distributed on the north slope of the Tianshan Mountains, but there are substantial climate differences and an uneven distribution of species across the mountain range from east to west. Therefore, studying the ecological adaptability of the same plant in different locations is the foundation for further exploring the potential of the plant. In this study, the differences in the phenotypic characteristics and biomass allocation of natural $B$. inermis were mainly regional, while the different elevations had little effect on these factors.

Our results showed that the degree of variation in the 11 phenotypic traits of natural $B$. inermis varied widely. This result is not surprising, as $B$. inermis is a cross-pollinated forage plant that exhibits variations in its offspring (Copete et al., 2018). Among them, the degrees of variation in nutrient acquisition traits (tiller number and root length) and 
growth traits (vegetative branch height and reproductive branch height) were relatively large. In other studies, we found that plant height was a strong indicator of the ability of a plant to adapt to climate change. During drought periods, upward stem growth is affected, which hinders an increase in plant height. Differences in water availability among different environments are an important factor leading to differences in plant height (Wang et al., 2010). We also found that tiller number, root length, spikelet traits, and stem and root biomass distribution did not change significantly among different environments, indicating that these traits were more stable. The degree of variation reflects the potential for variation in these traits in plants. Traits with a greater degree of variation are more suitable for research and are preferred as research materials, while more stable traits can provide materials for breeding. The principal component values of the traits indicated that the source of plant differences was the region, which is consistent with the ANOVA results described above. In the study of phenotypic traits, we found that the growth characteristics of reproductive branches, such as height, are the main factors affecting the differences in $B$. inermis; this finding is in line with trends in the genetic diversity of agronomic traits among gramineous grasses (Hao et al., 2011). In general, the phenotypic traits of $B$. inermis in the central section of the north slope of the Tianshan Mountains were superior to those of $B$. inermis in the eastern and western sections, indicating that these phenotypic traits exhibited certain regional adaptations.

Plants often need to change their phenotypic traits to respond and adapt to the heterogeneity of the environment during their long-term growth process. The correlation between environmental factors and plant traits indicates the response of the plant traits to the environment. The results of this study showed that most of the trait indicators were significantly correlated with geographical factors; most of these correlations were very significant correlations, though only a few indicators were correlated with soil factors. The relationship between traits and geographical factors is a focus of ecological research, and differences in temperature, rainfall and light factors lead to heterogeneity in the environmental conditions for plant growth. Testing plant performance under different environmental conditions can differentiate the optimal environment for plants from a suboptimal environment and determine the combination of traits that ensures the competitiveness of plants in both environments as well as the conditions at which the resource utilization rate of plants is highest. These methods can also be used to obtain plants suitable for increasing the range of a species, and this information is very useful for studying plant breeding for further range expansion.

\section{Biomass allocation adaptation capacity}

Biomass is an important indicator of the interaction between plants and the environment, and it is also the embodiment of plants' adaptability to the environment as well as their growth and development patterns. In addition, the biomass of individuals and components also reflects the capacity of an ecosystem to obtain energy (Michel et al., 2015). Vegetation responds to the availability of various resources through a variety of complex regulation systems, thus effectively improving the utilization efficiency of the entire ecosystem for limited resources (Stotz et al., 2017). To effectively adapt to the heterogeneity of the environment, the distribution of the total plant biomass to each component is not fixed. Rather, biomass allocation must be based on the influence of light, temperature, water, nutrients and other abiotic factors in the region, as well as on other plants in the community. Therefore, biomass allocation can be used as an indicator of the plant response to the environment, as it reflects whether the habitat is conducive 
to plant growth. Previous studies have obtained results regarding the biomass allocation of gramineous plant components under heterogeneous environments that are mostly similar to the results of this study (Zhao et al., 2018). The biomass input to stems and roots was greater than that to other components in different environments in this study, but some studies have shown that other plants allocate more biomass to their leaves than to their roots (Yang et al., 2009).

Nongrazed pastures were selected for this study, and the growth of plants was affected mainly by the natural environment. The results of the correlation analysis in this study show that the correlations of the environmental factors elevation, annual average temperature and annual average precipitation with the biomass distribution were stronger than others. Changes in elevation can cause differences in temperature and rainfall, so in the final analysis, the biomass allocation was affected mainly by these two factors. Tyree's study found that under insufficient water conditions, plants increased their biomass allocation to the stem mainly to reduce cavitation in the xylem (Hong et al., 2017) and stored more water to alleviate the water penetration that might occur in the stem. In this experiment, the stem biomass allocation ratio varied greatly among the different environments, which indicated that the water conditions were not consistent; the differences in the root biomass allocation ratio among different regions also corroborated this finding.

The results for the aboveground biomass and aboveground component biomass in this study confirmed that the biomass allocation to the stem was more closely related to the total aboveground biomass than the biomass allocation to other plant components. In a number of simulated-rainfall experiments, it was found that a reduction in rainfall was beneficial to the growth of belowground plant parts because the reduction in water stimulated the uptake of water by roots, thus increasing the biomass of roots and the absorption of nutrients such as nitrogen and phosphorus (Liu et al., 2018). Decreases in rainfall have no significant effect on overall plant biomass because while plants will increase their root biomass under low-water conditions, they will also reduce their leaf biomass to avoid excessive water loss from evapotranspiration. In this study, the leaf biomass remained relatively stable across the 5 regions, which represents a resource allocation strategy for plants in unique environments (Huxman et al., 2004).

Previous studies have found that an increase in temperature is conducive to the accumulation of plant biomass and that plants are more inclined to allocate biomass to their aboveground parts, especially the stems, under warmer conditions (Wal and Stien, 2016). The aboveground biomass is not only related to the $\mathrm{CO}_{2}$ fixation ability of a plant but is also closely related to the total biomass of the plant; the accumulation of belowground biomass is conducive to the absorption of water and nutrients. In a study of the effects of temperature on plants, it was found that a high belowground biomass/aboveground biomass ratio was an adaptive strategy for cold environments (Ma et al., 2010) because low temperature inhibited the root turnover rate, resulting in an increase in belowground biomass (Yang et al., 2009). In this study, the aboveground biomass of $B$. inermis in Hutubi County and Urumqi County was larger than that in other counties, and the total biomass was also higher than that in the other areas. This was due to the abundant rainfall and light in these two counties; determining whether the $B$. inermis (smooth brome) growing in these areas has special growth characteristics and whether it can become a source of high-quality breeding varieties will require further research (Chen and Zhang, 2012). The distribution of aboveground biomass and belowground biomass in $B$. inermis in the other three regions was relatively balanced, 
which ensured a supply of sufficient nutrients and water to meet the demands of reproductive growth (Mateus $\mathrm{H}$ et al., 2015).

Plants, by adjusting the allocation of their biomass, balance their investment in each organ across different environments. The aboveground and belowground biomass and the balance of nutrient acquisition and reproductive biomass show the distribution of different resource acquisition strategies of plants of the same species. In this study, we found that plants respond to the environment more through the plasticity of their phenotypic traits than by adjusting their biomass allocation.

\section{Conclusion}

According to our field investigation experiments, significant phenotypic characteristic variation was observed between different regions, and little variation was observed within regions. Habitat heterogeneity also affected the geographic variation of the phenotypic traits of B. inermis. Some traits were strongly affected by environmental effects, among which the vegetative branch height, leaf width, panicle characteristics and stem diameter are suitable for studies that need to be sensitive to environmental effects. More resources were invested in vegetative organs than in nutrient acquisition organs, which indicated that plants were more inclined to regenerate and expand their population through asexual reproduction. The aboveground organs were closely related to the aboveground biomass allocation, which was more conducive to plants adapting to an environment with frequent temperature and water changes by coordinating their various organs.

This study provides basic information regarding the phenotypic diversity of $B$. inermis and its potential breeding sources. B. inermis in the central part of the north slope of the Tianshan Mountains showed obvious advantages. It is the most promising germplasm resource identified in this study due to its high plant height, wide leaves and high material yield. $B$. inermis has the ability to adapt to different environments, which suggests that it has the ability to withstand local and global climate changes. Further field experiments will help to reveal the phenotypic adaptability of $B$. inermis in different environments and will provide a reference for future work on phenotypic gene mapping and gene screening.

Acknowledgements. The authors would like to acknowledge the contributions and support of College of Grassland and Environmental Sciences, Xinjiang Agricultural University, Key Laboratory of Grassland Resources and Ecology of Xinjiang.

Author contributions. Jin, G. L. conceived the ideas; Gong, K. conducted the experiments and prepared samples. L.W.H. and G.K. collected the data; L.W.H. and G.K. analysed the data; G.K. wrote the manuscript. All authors contributed critically to the drafts.

Funding information. This research was funded by the Grassology Peak Discipline Foundation of the Xinjiang Uygur Autonomous Region, China (CXGFXK-2019-03), China Forage and Grass Research System (CARS34).

Conflict of interests. The authors declare that they have no conflict of interests.

\section{REFERENCES}

[1] Biligetu, B., Coulman, B. (2011): Leaf area expansion and net photosynthetic rate of three bromegrass (Bromus) species. - Photosynthetica 49(3): 478-480. 
[2] Bobowicz, M. A., Krzakowa, M. (1986): Anatomical differences between Pinus mugs Truro populations from the Tarts Mts. expressed in needle traits and in needle and cone traits together. - Acta Societatis Botanicorum Poloniae 55(2): 275.

[3] Bradshaw, A. D. (1965): Evolutionary significance of phenotypic plasticity in plants. Advances in Genetics 13(1): 115-155.

[4] Chen, J. H., Zhang, Y. M. (2012): Strategies for biomass allocation of two desert plant species under water stress. - Arid Zone Research 29(03): 432-439.

[5] Copete, A., Moreno, R., Cabrera, A. (2018): Characterization of a world collection of Agropyron cristatum accessions. - Genet Resour Crop Evol. 65: 1455-1469.

[6] Duruflé, H., Ranocha P., Mbadinga, D. M, et al. (2019): Phenotypic trait variation as a response to altitude-related constraints in Arabidopsis populations. - Frontiers in Plant Science 10.

[7] Hao, F., Xu, Z., Li, P., et al. (2011): Genetic diversity of Bromus inermis on agronomic traits. - Pratacultural Science 28(05): 769-776.

[8] Hong, J. J., Liu, S., Glover, P., et al. (2017): Mathematical and experimental investigation of water migration in plant xylem. - J Bionic Eng 14(4): 622-630.

[9] Huxman, T. E., Smith, M. D., Fay, P. A., et al. (2004): Convergence across biomes to a common rain-use efficiency. - Nature 429: 651-654.

[10] Lermi, A. G., Erdogdu, Altinok, S. (2018): The effects of chemical and organic fertilizer applications on forage yield and quality of smooth brome (Bromus inermis L.) under irrigated and non-irrigated conditions. - Applied Ecology and Environmental Research 16(5): 6087-6094.

[11] Li, X., Liu, Z., Wang, Z., et al. (2015): Pathways of Leymus chinensis individual aboveground biomass decline in natural semiarid grassland induced by overgrazing: a study at the plant functional trait scale. - Plos One 10(5): 192-205.

[12] Liu, H., Mi, Z., Lin, L., et al. (2018): Shifting plant species composition in response to climate change stabilizes grassland primary production. - Proceedings of the National Academy of Sciences of the United States of America 115(16), 4051-4056.

[13] Lu, J. J., Tan, D. Y., Baskin, J. M., et al. (2012): Phenotypic plasticity and bet-hedging in a heterocarpic winter annual/spring ephemeral cold desert species of Brassicaceae. Oikos 121, 357-366.

[14] Luo, Y. J., Wang, X. K., Zhang, X. Q., et al. (2012): Root: shoot ratios across China's forests: forest type and climatic effects. - Forest Ecology and Management 269: 19-25.

[15] Ma, W. L., Shi, P. L., Li, W. H., et al. (2010): Changes in individual plant traits and biomass allocation in alpine meadow with elevation variation on the Qinghai-Tibetan Plateau. - Science in China Series C: Life Sciences 53(9): 1142-1151.

[16] Majidi, M. M., Bahrami, S., Abtahi, M., et al. (2017): Genetic analysis of seed-related traits in smooth bromegrass (Bromus inermis) under well-watered and water-stressed conditions. - Grass and Forage Science 72(1).

[17] Mateus, H. V., Agustin, Z., Ariadne, F. L., et al. (2015): Semi-determinate growth habit adjusts the vegetative-to-reproductive balance and increases productivity and water-use efficiency in tomato (Solanum lycopersicum). - Journal of Plant Physiology, 177: 11-19.

[18] McKown, A. D., Guy, R. D., Klapste, J. (2014): Geographical and environmental gradients shape phenotypic trait variation and genetic structure in Populus trichocarpa. New Phytol 201(4): 1263-1276.

[19] Meng, T. T., Ni, J., Wang, G. H. (2007): Plant functional traits, environments and ecosystem functioning. - Journal of Plant Ecology 31: 150-165.

[20] Michel, Loïc, N., et al. (2015): Selective top-down control of epiphytic biomass by amphipods from Posidonia oceanica meadows: implications for ecosystem functioning. Belgian Journal of Zoology 145(2): 83-93

[21] Morgenstern, M. (2011): Geographic Variation in Forest Trees: Genetic Basis and Application of Knowledge in Silviculture. - University of British Columbia Press, Vancouver, pp. 3-18. 
[22] Olowa, L. F., Lalisan, J. A., Ma, R. (2018): Leaves of Tectaria dissecta ((G. Forst.) Lellinger) collected from three elevations in Tinago Falls, Iligan City exhibit morphological variation using fractal analysis. - Electronic J Biol 13: 4.

[23] Ott, J. P., Butler, J. L., Rong, Y. (2017): Greater bud outgrowth of Bromus inermis than Pascopyrum smithii under multiple environmental conditions. - Journal of Plant Ecology 10(3): 518-527.

[24] Pang, T. Y., Lercher, M. (2015): Evolution of complex phenotypes through successions of adaptive steps. Quantitative Biology. - arXiv: Populations and Evolution Corpus ID: 1744841

[25] Peltonen-Sainio, P., Jauhiainen, L., Hakala, K. (2011): Crop responses to temperature and precipitation according to long-term multi-location trials at high-latitude conditions. Journal of Agricultural Science 149(1): 49-62.

[26] Sadras, V. O., Slafer, G. A. (2012): Environmental modulation of yield components in cereals: heritabilities reveal a hierarchy of phenotypic plasticities. - Field Crops Research 127: 215-224.

[27] Salesman, J. B., Thomsen, M. (2011): Smooth brome (Bromus inermis) in tallgrass prairies: a review of control methods and future research directions. - Ecological Restoration 29(4): 374-381.

[28] Slafer, G. A., Savin, Sadras, V. O. (2014): Coarse and fine regulation of wheat yield components in response to genotype and environment. - Field Crops Research 9(3): 158169.

[29] Stotz, G. C., Gianoli, E., Patchell, M. J., et al. (2017): Differential responses of native and exotic plant species to an invasive grass are driven by variation in biotic and abiotic factors. - Journal of Vegetation Science 28(2): 325-336.

[30] Ulrich, E., Perkins, L. (2014): Bromus inermis and Elymus canadensis but not Poa pratensis demonstrate strong competitive effects and all benefit from priority. - Plant Ecology 215(11): 1269-1275.

[31] Wal, R., Stien, A. (2016): High-arctic plants like it hot: a long-term investigation of between-year variability in plant biomass. - Ecology 95(12).

[32] Wang, Y. H., Yu, F. H., Dong, M., et al. (2010): Growth and biomass allocation of Lolium perenne seedlings in response to mechanical stimulation and water availability. Annales Botanici Fennici 47(5): 367-372.

[33] Wang, R. Z., Huang, W. W., Chen, L., et al. (2011): Anatomical and physiological plasticity in Leymus chinensis (Poaceae) along large-scale longitudinal gradient in Northeast China. - PLoS ONE 6(11): 374-381.

[34] Woodis, J. E., Jackson, R. D. (2010): The effects of clipping height and frequency on net primary production of Andropogon gerardii ( $\mathrm{C} 4$ grass) and Bromus inermis ( $\mathrm{C} 3$ grass) in greenhouse experiments. - Grass and Forage Science 63. https://doi.org/10.1111/j.13652494.2008.00653.x.

[35] Xu, X., Niu, S. L., Sherry, R. A., et al. (2012): Interannual variability in responses of belowground net primary productivity (NPP) and NPP partitioning to long-term warming and clipping in a tallgrass prairie. - Global Change Biology 18: 1648-1656.

[36] Yang, Y. H., Fang, J. Y., Ji, C. J., et al. (2009): Above- and belowground biomass allocation in Tibetan grasslands. - Journal of Vegetation 1: 177-184.

[37] Yang, X. P., Li, P., Dong, C. F., et al. (2020): Studies on the dynamics of above-ground biomass and nutritive values of annual ryegrass and common oat. - Acta Agrestia Sinica 28(01): 149-158.

[38] Yuan, J., Wang, P., Yang, Y. (2019): Effects of simulated herbivory on the vegetative reproduction and compensatory growth of Hordeum brevisubulatum at different ontogenic stages. - International Journal of Environmental Research and Public Health 16(9): 1663-1671. 
[39] Zhang, J., Li, X., Zhuang, L., et al. (2015): Growth forms of Leymus chinesis (Poaceae) at the different developmental stages of the natural population. - Plant Species Biology 29(3): 263-271.

[40] Zhao, N. X., Zhang, L. H., Zhao, T. T., et al. (2016): Trait differentiation among Stipa krylovii populations in the Inner Mongolia Steppe region. - Flora 223: 90-98.

[41] Zhao, P. P., Li, G. Q., Shao, W. S., et al. (2018): Influence of herbivore exclusion on the soil seed bank and the aboveground vegetation characteristics of Agropyron mongolicun dominant desert steppe grassland. - Acta Prataculturae Sinica 27(1): 42-52.

[42] Zheng, S., Zhu, H., Wang, X. R., et al. (2019): Environment-dependent phenotypic variation of Osmanthus fragrans. - Journal of Nanjing Forestry University (Natural Sciences Edition). 